Prof Rachel Barker

UNISA

Dr Derek Ong
SUNWAY University; Malaysia

DOI: $h$ ttp://dx.doi. org/10.18820/2519593X/pie. v34i2.1

ISSN 0258-2236

e-ISSN 2519-593X

Perspectives in Education

2016 34(2): $1-18$

(c) UVIUFS

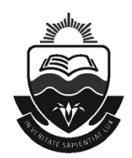

\section{A measurement scale for students' usage of online networks}

\begin{abstract}
Studies suggest that students are increasingly turning to information and communication technologies as learning tools in which they can present multiple identities quite explicitly tied to context, knowledge and understanding within online networks. Hence it is imperative for educational institutions to understand how twenty-first-century learners use online networks for their identity formation and learning experiences. Through a systematic review of existing instruments, constructs and elements were identified and used to develop a new conceptual research framework which was quantitatively tested on a convenience sample of students $(n=300)$ at Sunway University in Malaysia. Based on the results, a measurement scale was developed and analysed through structural equation modelling and confirmatory factor analysis. The responses of the students revealed they are more likely to use online networks for identity formation than for the learning experience and that there is a relationship between identity formation, the learning experience and the use of online networks.
\end{abstract}

Keywords: Identity formation, learning experience, online networks, structural equation modelling, knowledge management

\section{Introduction}

Cheung, Chiu and Lee (2011: 1337) define online networks as virtual communities where people connect and interact with each other on a specific topic or where they just 'hang out' together at a social level. In recent years, research on the use of online networks in learning virtual environments has become as powerful as the technological change in the history of the globalised world, yet there is a lack of theorydriven empirical research. For example, Boyd and Ellison (2007) emphasise that a lack of studies exist to explore the link between online networks and education. This is echoed by Walker and Gleaves (2014), who confirm that a lack of rich qualitative studies to better theorise the learning experience and students' perception of learning value and the status of knowledge created by others is evident in the literature. It was again reiterated in the opening speech of Will Swann (President of EADTU) when he accentuated the tremendous experience possible in online networks for students' learning activities in terms of practical knowledge and discovering skills. Using these online networks, they are able to learn from the many virtual learning environments in 
which students and staff can interact through the application of online teaching and learning methods without physical presence (Sancho \& De Vries, 2014). This paper set out to address the gaps outlined above by focusing on an interpretivistic communicative perspective based on the knowledge management theory with the main objective to propose and test a new theoretical measurement scale for students' usage of online networks for their identity formation and learning experience.

\section{Literature review and theoretical framework}

In order to present a theoretical discussion of identity formation and the learning experience in online networks, a number of notional constructs are briefly presented. Firstly, identity formation, which is usually studied from philosophical, social and psychological points of view thereby, makes it possible to study identities in social groups or online networks from different perspectives. According to Rimsky (2011: 79-80), the interpretation of identity most appropriate for the analysis of identity formation in online networks is that it is,

the state of the individual's consciousness in which, on the basis of the aggregate set of personal characteristics, one knows oneself, one recognizes the stability of one's own personality, one determines oneself from the surrounding reality, and one determines one's membership in a particular social group and, conversely, acknowledges the impossibility of belonging to other social groups.

Secondly, online networks are webs of relationships that grow from computer-mediated discussions and conversations among people who share a common affinity and articulate a shared connection but differ and traverse in other ways (distance, time comprehension, embeddedness in single locations, etc.) (Barker, 2011). In the context of this study, the definition of Boyd and Ellison (2007) has been adapted. According to this definition, online networks refer to web-based services which allow individuals to construct a profile (identity formation) within a bounded system articulated by other users (usage patterns) with whom they share the connection and how they perceive the connections and feedback (learning experience) that take place within this system. According to Attrill and Jalill (2010: 1635), trust, the social setting, social identity, intent, privacy and the type of information that individuals are willing to expose or present on their profiles are the factors that will impede or influence identity formation in online networks.

Thirdly, the learning experience which according to Greenhow and Robelia (2009: 119), refers to the contexts for learning which are becoming increasingly complex across a range of physical and cyberspaces - especially in terms of how students' learning experiences in online networks are transforming education. If applied to online networks, the learning experience is dependent on information and knowledge obtained through interactions and transmitted ubiquitously through social interactions without considering real-world consequences. This is confirmed by Kirkwood (2008), who found that students search for information or knowledge for their homework, assignments and studies; and Hung and Chung (2013), who argue that online networks serve as storehouses of knowledge in which information and knowledge creation and sharing are growing rapidly for problem-solving and learning purposes at universities. Although some authors (Brown, 2011; Hara \& Kling, 2000) argue that drawbacks like feelings of isolation, loneliness, frustration, anxiety and confusion might reduce students' learning experiences, a study conducted by Chou and Liu (2005) indicates that a relationship does exist between learner control and learning effectiveness. Furthermore, extroverts are more likely to experience benefits from their Internet usage than introverts and other authors 
like Bargh and McKenna (2004) confirm that it positively influences psychological well-being. A recent study by Young and Strelitz (2014) concludes that Facebook usage is socially patterned, is based on race and class variables but is weakly associated with loneliness and well-being.

According to Chan, Walker and Gleaves (2015: 97) a lack of consensus has exposed two distinct areas in the theorisation of online learning, namely a field of technological affordance distinct from e-learning and broadly defined in terms of educational relevance and how it is exemplified through the ubiquitous and personalised use of technology. This study hence draws from integrative theoretical models that document and stresses the need to consider usage patterns. Furthermore, based on the argument earlier that successful online networks are characterised by the constant creation and sharing of new knowledge and the fast dissemination and representation thereof as well as commitment to and understanding of individuals in the online networks, the main thrusts of the research were critically viewed and analysed from a knowledge management perspective. Based on the viewpoint of Farquhar and Rowley (2006: 162) that institutions with power over online networks as technological e-learning developments are in a better position to dominate and manage interactions on the Internet, it is argued that this network society offers the opportunity to knowledge-based institutions to build, enhance and maintain sustainable communication relationships with individuals through knowledge creation and sharing. In the context of this study, knowledge management is defined "as the generation, storing, representation and sharing of knowledge to the benefit of the organisation and its individuals, it is arguably specifically relevant to study the use of online networks for identity formation and the learning experience through knowledge creation and sharing" (Barker, 2011: 334-350).

Based on this approach, as well as an extensive literature search using these concepts and applying inclusion and exclusion criteria, six instruments were selected of which criteria have been used for the purpose of this study. The findings of this review indicated that the most appropriate elements to use in order to study these concepts from an integrated approach are the ones presented in the theoretical framework in figure 1.

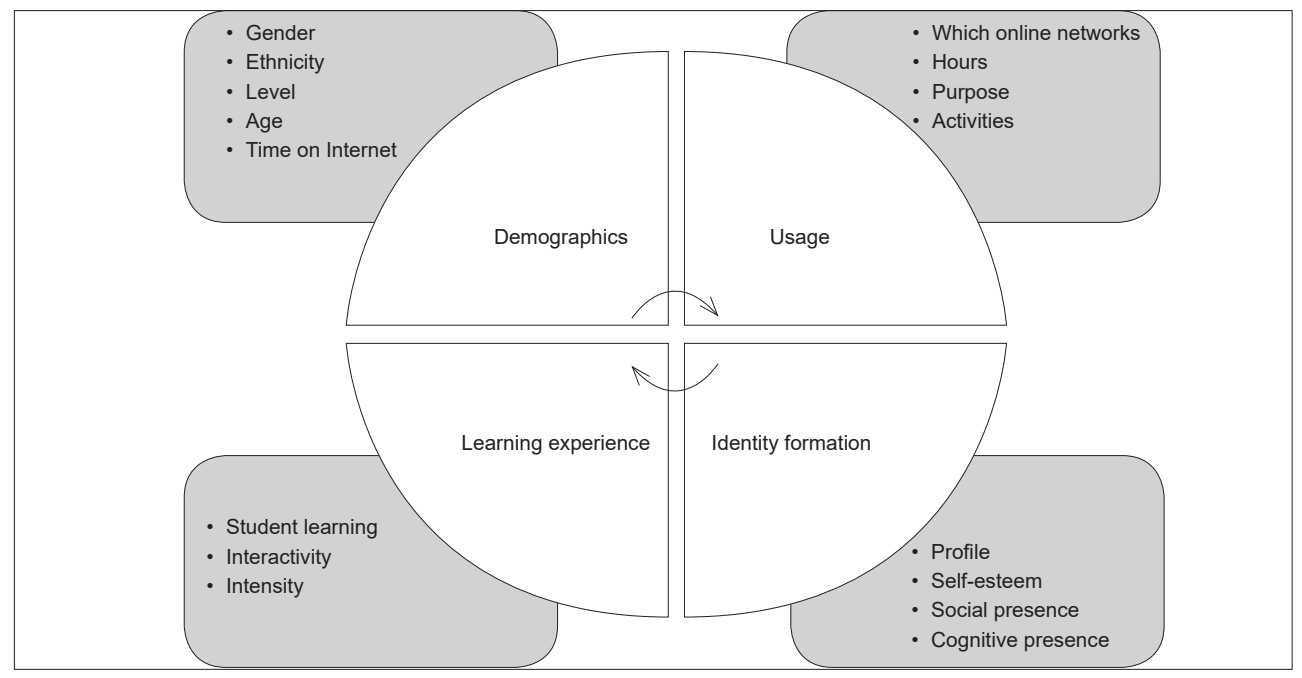

Figure 1: Theoretical research framework 
This framework has been developed and based on an integration of concepts from existing instruments and questionnaires, grounded in a comprehensive review of literature. These concepts are demographics (Ellison, Steinfeld \& Lampe, 2007: 1149), usage (Ellison et al., 2007: 1150) and identity formation (identity profile of LaRose et al., 2005; self-esteem from Rosenberg's 1989 self-esteem scale, updated by Ellison et al. 2007: 1152; social presence and cognitive presence of Garrison, Cleveland-Innes \& Fung 2004: 67). It also includes the concept of learning experience (student learning from Garrison et al., 2004: 72-73 and Pempek, Yermolayeva \& Calvert, 2008: 233; interactivity from Garrison et al., 2004; Pempek et al., 2008: 234 and intensity from Ellison et al., 2007: 1150).

\section{Research design}

To address the research problem that a lack of existing instruments exist to measure the usage of online networks, this study set out to develop and empirically test a new measurement model based on the argument that a triadic relationship exists between online networks, identity formation and the learning experience. Based on the preceding theoretical discussion, corroborated by Bonboni and Pinho (2013: 223), stating that existing approaches do not "fully capture the richness of the concept by not taking into account the social identity dimension, which reflects the main aspects of the individual's identification". Therefore, a new conceptual framework integrating existing measurement tools and concepts as shown in figure 2 have been developed to address this gap and were used in this study.

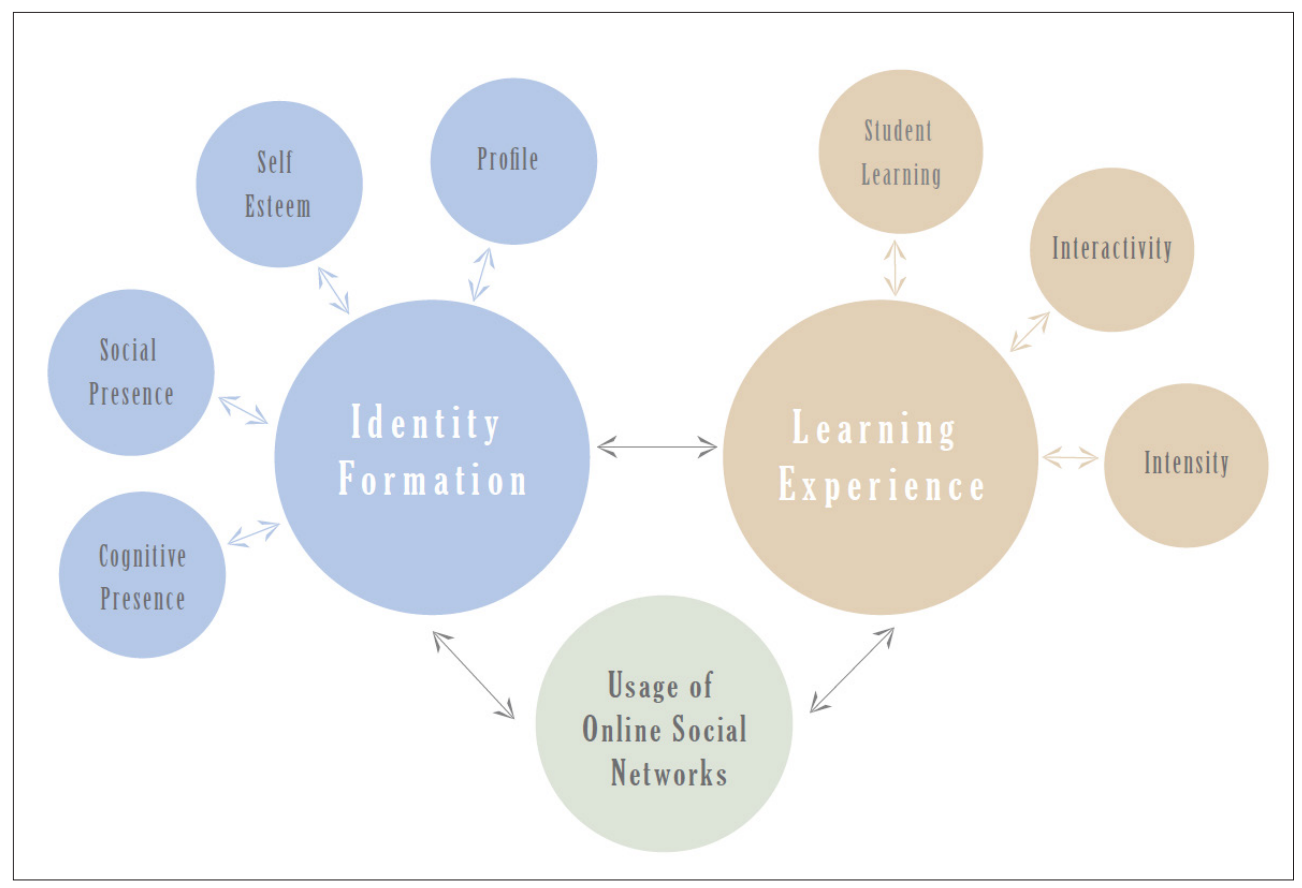

Figure 2: Conceptual framework to measure the impact of the usage of online networks 


\section{Methodology}

\subsection{Sample}

This study empirically tested the above conceptual framework, which links the usage of online networks, identity formation and the learning experience. The study population comprised students at a private university. A convenience sample of planned $n=320$ was therefore selected from students studying BSc (Hons) Business Degree programmes at the Sunway University in Malaysia. This sample was chosen based on the representation of the university's students as Sunway University has one of the biggest student populations (for private higher education institutions in Malaysia) and the students from the Business School has the highest number of enrolment for the entire university. A combination of quantitative survey methods and a qualitative literature review formed the core of the data that were used for this study.

\subsection{Measures}

Before administration of the survey, a preliminary survey was conducted with 43 students in October 2014. The results indicated that the wording of questions was clear but that 21 of the 87 items did not indicate any significance. To increase the reliability of the measure, these items were removed. After the pilot test, a 66-item instrument comprising seven sub-constructs was developed where the alpha values reported in brackets are Cronbach's reliability coefficients for each construct; profile $(\alpha=0.614)$, self-esteem $(\alpha=0.774)$, social presence $(\alpha=0.894)$, cognitive presence $(\alpha=0.786)$, student learning ( $\alpha=0.875)$, interactivity $(\alpha=0.843)$ and intensity $(\alpha=0.725)$. The Cronbach alpha for each of these constructs was between 0.6 and 0.8 , which implies that the reliability of these constructs was acceptable and it can be considered that there was substantial agreement between them. These constructs were identified based on the proposed conceptual framework for theoretical research developed for this study, obtained through a thorough literature review. Theoretical statements, which are defined as summaries of central assumptions; suppositions; conjectures and assertions of declarations based on certain theories, models or the literature were used in the compilation of the questionnaires and were adapted based on the results of the pilot study - that is, those factors with no significant indicators were removed (Taylor et al., 2011: 3). The measurement scale used for the closed-ended questions was the seven-point Likert scale $(1=$ strongly disagree to 7 = strongly agree). The survey data were then collected in November/December 2014 from a sample of students randomly selected in the classrooms. A short description of the study, information about confidentiality and an incentive for participation resulted in a realised sample of 301 ( $n=301$; several classes did not have full attendance at the time of data collection) from the 320 students initially selected and confirmed that there were no missing data. The proposed measurement model in figure 2 was measured using reliability and construct measurement measures in SMARTPLS to determine the cohesiveness of the items used to measure each construct.

\section{Results}

\subsection{Descriptive characteristics}

The descriptive characteristics of respondents' demographic information indicated that from the realised sample $(n=301), 191$ respondents were male $(63 \%)$ and 110 were female $(37 \%)$. Most of the students were Chinese (85\%), Indian (6\%) and Malaysian (5\%), with the majority of students being between the ages of 18 to 20 years $(81 \%)$, followed by 20 to 25 years 
(18\%); only $1 \%$ were younger than 18 years. Interestingly, most of the students who used online networks were at first-year level $(73 \%)$, followed by second-year level and honours level (both at 11\%) and third-year level (only 5\%). The reasons they gave for their usage of online networks were as follows: Facebook (social interaction $n=267$ and to stay on trend $n=226$, but still a high result for using it for personal information $n=122$ ). They also used Facebook for learning purposes $(n=103$ ), E-learn (for learning purposes $n=26$ ) and Twitter (social interaction $n=133$ and to stay on trend $n=108$ ). It is clear that E-learn is mostly used for learning purposes; it scored the lowest for social interaction. An interesting observation is that Twitter scored fairly high on usage for learning purposes compared to the remaining online networks, while MySpace was not used at all. It can be deduced that, in general, the online networks Facebook, E-learn and Twitter are indeed used for learning purposes and that students rely more on Facebook, Twitter and other online networks for their identity formation. Most students had more than 50 online connections on Facebook $(n=238)$, followed by Twitter $(n=107)$. A substantial number of respondents $(n=151)$ had fewer than 20 connections on E-learn, which is quite interesting as this is the formal online networks of the university.

\subsection{Results of the measurement model}

The proposed measurement model was analysed and interpreted in two stages: an assessment of the construct validity of the measurement model through common method variance (CMV) factor analysis and an assessment of the structural model. All the subconstructs in the structural model were specified as latent variables. The following section explains these stages.

\subsubsection{CMV factor analysis: SMARTPLS}

Data collected may be subject to self-reported biasness, which could mean that there may be a potential for CMV biasness. Conway and Lance (2010: 328) mention "that it is widely assumed that common method bias inflates relationships between variables measured by self-reports". The Harman one-factor test (CMV biasness) was conducted to determine the extent of biasness in various proportion distributions of the items (Ramayah et al., 2011). According to Podsakoff and Organ (1986), common method bias is problematic if a single latent factor would account for the majority of the explained variance; in this case, it would be more than $50 \%$. In this study, the un-rotated factor analysis showed that the one factor accounted for only $31.56 \%$ of the total variance and thus the common method bias was not a serious threat.

The CMV, using factor analysis by forcing all the measurements into one single factor, appears to be less than $50 \%$, indicating that no major common method problems were evident; hence, the researchers proceeded with the building of the measurement model. Once all the data was finally ready to be fitted into a structural equation model (SEM), the data was imported into SMARTPLS software for analysis. The measurement model was deemed valid because the usage of an SEM implied that it complied with the definition proposed by Hair et al. (2010: 636), namely "the rules of correspondence between measure and latent variables (constructs) were accessed for their validity". The results are indicated in figure 3. 


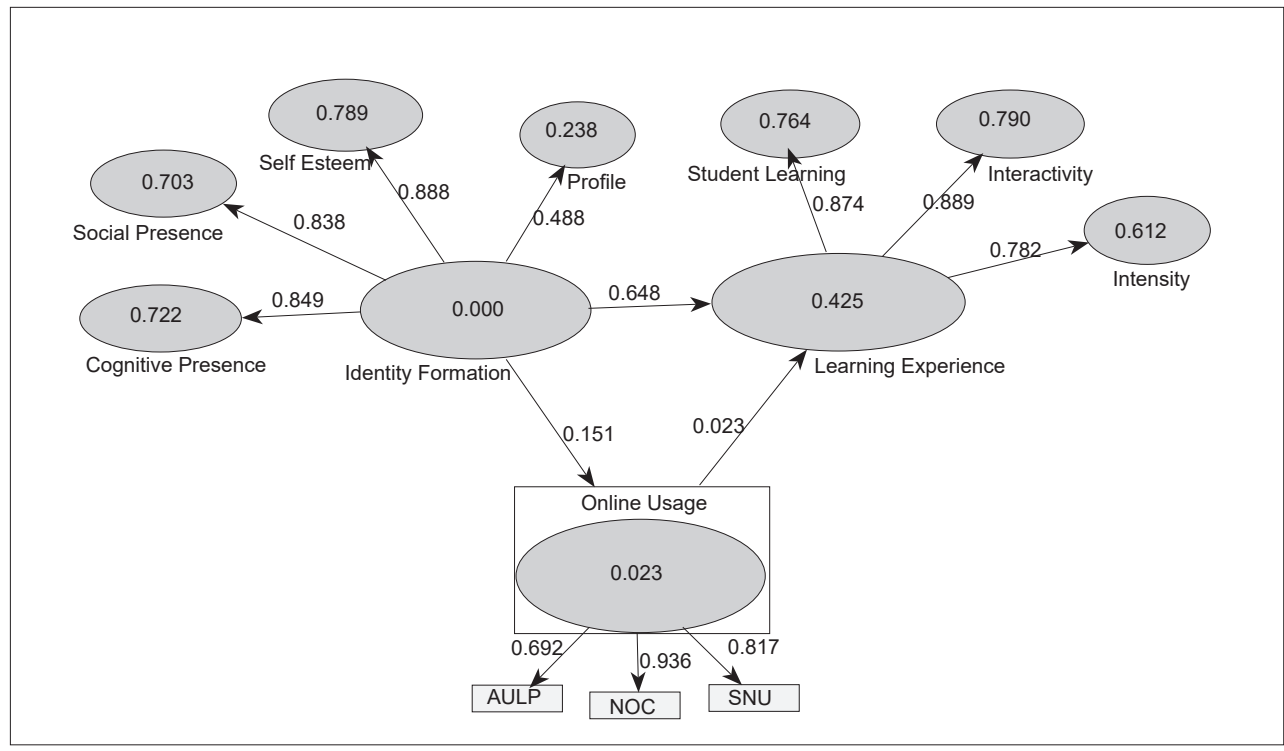

Figure 3: Measurement model

\subsubsection{Reliability and validity}

Indicator reliability denotes the proportion of indicator variance that is explained by the latent variable, which is between 0 and 1 . When the indicator and latent variables are standardised, the indicator reliability equals the squared indicator loading, which should normally be approximately 0.25 to 0.5 . Reflective indicators with loadings within the PLS model that were less than 0.4 were removed (Hulland, 1999: 198). Because loadings of measurements $<0.5$ suggest a negligible effect, these items were removed, as indicated in table 1.

Table 1: Measurements removed

\begin{tabular}{|l|l|l|}
\hline \multicolumn{1}{|c|}{ Constructs } & \multicolumn{1}{c|}{ Removed Item } & \multicolumn{1}{c|}{ Definition } \\
\hline Online Usage & AUWE & Average Usage Weekends \\
\hline & AUWD & Average Usage Weekdays \\
\hline Profile & IYS 4, IYS 6 - IYS13 & \\
\hline Self Esteem & NONE & \\
\hline Social Presence & PYA 1, PYA 2 & \\
\hline Cognitive Presence & NONE & \\
\hline Student Learning & OLE 3 & \\
\hline Interactivity & NONE & \\
\hline Intensity & IWO 1, IWO 3,IWO4 & \\
\hline
\end{tabular}

To achieve convergent reliability, the average variance extracted (AVE) was calculated. The AVE is comparable to the proportion of variance explained in factor analysis, with values again ranging from 0 and 1. As explained by Bagozzi and Yi (1988) and Fornell and Larcker (1981), 
a latent variable with an AVE exceeding 0.5 suggests adequate convergent reliability (CR). The calculations of the AVE and CR are presented in table 2.

Table 2: Calculation of the average variance extracted and the convergent reliability

\begin{tabular}{|l|c|c|}
\hline & AVE & CR \\
\hline Online Usage & 0.673614 & 0.859164 \\
\hline Cognitive Presence & 0.553029 & 0.896283 \\
\hline Self Esteem & 0.542525 & 0.928344 \\
\hline Social Presence & 0.561755 & 0.899171 \\
\hline Profile & 0.573781 & 0.843248 \\
\hline Student Learning & 0.503428 & 0.901022 \\
\hline Interactivity & 0.611696 & 0.933949 \\
\hline Intensity & 0.604507 & 0.883533 \\
\hline Identity Formation & 0.612 & 0.858 \\
\hline Learning Experience & 0.722 & 0.886 \\
\hline
\end{tabular}

Tables 3 and 4 present the calculations for identity formation and learning experience respectively.

Table 3: Calculation for identity formation

\begin{tabular}{|l|l|l|l|}
\hline \multicolumn{4}{|c|}{ Calculation for Identity Formation } \\
\hline & STD Loading & STD Loading squared & $\begin{array}{l}\text { Error Variance = 1- loadings } \\
\text { squared }\end{array}$ \\
\hline Cognitive Presence & 0.849 & 0.720801 & 0.279199 \\
\hline Social Presence & 0.838 & 0.702244 & 0.297756 \\
\hline Self Esteem & 0.888 & 0.788544 & 0.211456 \\
\hline Profile & 0.488 & 0.238144 & 0.761856 \\
\hline & & & 1.550267 \\
\hline Total Loadings & 3.063 & 2.449733 & \\
\hline Total Loadings Squared & 9.381969 & & 10.932236 \\
\hline & & & \\
\hline & AVE & 0.612 & 0.858 \\
\hline & $\begin{array}{l}\text { Composite } \\
\text { Reliability }\end{array}$ & & \\
\hline
\end{tabular}


Table 4: Calculation for learning experience

\begin{tabular}{|l|l|l|l|}
\hline \multicolumn{5}{|c|}{ Calculation for Learning Experience } \\
\hline & Std. Loading & STD Loading squared & $\begin{array}{l}\text { Error Variance }= \\
\text { 1- loadings squared }\end{array}$ \\
\hline Student Learning & 0.874 & 0.763876 & 0.236124 \\
\hline Interactivity & 0.889 & 0.790321 & 0.209679 \\
\hline Intensity & 0.782 & 0.611524 & 0.388476 \\
\hline & & & \\
\hline Total Loadings & 2.545 & 2.165721 & 0.834279 \\
\hline Total Loadings Squared & 6.477025 & & 7.311304 \\
\hline & & & \\
\hline & AVE & 0.722 & 0.886 \\
\hline & Composite Reliability & & \\
\hline
\end{tabular}

Based on the above, the full measurement model is presented in table 5.

Table 5: Full measurement model

\begin{tabular}{|c|c|c|c|c|c|c|c|}
\hline 2nd Order Construct & AVE & CR & Construct & Item & Loadings & AVE & CR \\
\hline & & & Online Usage & AULP & 0.692 & 0.674 & 0.859 \\
\hline & & & & NOC & 0.936 & & \\
\hline & & & & SNU & 0.817 & & \\
\hline Identity Formation & 0.612 & 0.858 & $\begin{array}{l}\text { Cognitive } \\
\text { Presence }\end{array}$ & YP_1 & 0.690 & 0.553 & 0.896 \\
\hline & & & & YP_2 & 0.752 & & \\
\hline & & & & YP_3 & 0.775 & & \\
\hline & & & & YP_4 & 0.693 & & \\
\hline & & & & YP_5 & 0.786 & & \\
\hline & & & & YP_6 & 0.764 & & \\
\hline & & & & YP_7 & 0.739 & & \\
\hline & & & Self Esteem & SYS_1 & 0.707 & 0.543 & 0.928 \\
\hline & & & & SYS_10 & 0.709 & & \\
\hline & & & & SYS_11 & 0.676 & & \\
\hline & & & & SYS_2 & 0.830 & & \\
\hline & & & & SYS_3 & 0.707 & & \\
\hline & & & & SYS_4 & 0.810 & & \\
\hline
\end{tabular}




\begin{tabular}{|c|c|c|c|c|c|c|c|}
\hline 2nd Order Construct & AVE & CR & Construct & Item & Loadings & AVE & CR \\
\hline & & & & SYS_5 & 0.747 & & \\
\hline & & & & SYS_6 & 0.806 & & \\
\hline & & & & SYS_7 & 0.661 & & \\
\hline & & & & SYS_8 & 0.777 & & \\
\hline & & & & SYS_9 & 0.645 & & \\
\hline & & & Social Presence & PYA_3 & 0.623 & 0.562 & 0.899 \\
\hline & & & & PYA_4 & 0.737 & & \\
\hline & & & & PYA_5 & 0.774 & & \\
\hline & & & & PYA_6 & 0.806 & & \\
\hline & & & & PYA_7 & 0.802 & & \\
\hline & & & & PYA_8 & 0.771 & & \\
\hline & & & & PYA_9 & 0.717 & & \\
\hline & & & Profile & IYS_1 & 0.734 & 0.574 & 0.843 \\
\hline & & & & IYS_2 & 0.796 & & \\
\hline & & & & IYS_3 & 0.740 & & \\
\hline & & & & IYS_5 & 0.679 & & \\
\hline \multirow[t]{16}{*}{ Learning Experience } & 0.772 & 0.886 & Student Learning & OLE_1 & 0.661 & 0.503 & 0.901 \\
\hline & & & & OLE_10 & 0.710 & & \\
\hline & & & & OLE_2 & 0.725 & & \\
\hline & & & & OLE_4 & 0.693 & & \\
\hline & & & & OLE_5 & 0.754 & & \\
\hline & & & & OLE_6 & 0.740 & & \\
\hline & & & & OLE_7 & 0.752 & & \\
\hline & & & & OLE_8 & 0.669 & & \\
\hline & & & & OLE_9 & 0.675 & & \\
\hline & & & Interactivity & OCl_1 & 0.750 & 0.612 & 0.934 \\
\hline & & & & OCl_2 & 0.687 & & \\
\hline & & & & OCl_3 & 0.823 & & \\
\hline & & & & OCl_4 & 0.760 & & \\
\hline & & & & OCl_5 & 0.809 & & \\
\hline & & & & OCl_6 & 0.804 & & \\
\hline & & & & OCl_7 & 0.799 & & \\
\hline
\end{tabular}




\begin{tabular}{|l|l|l|l|c|c|c|c|}
\hline 2nd Order Construct & AVE & CR & Construct & Item & Loadings & AVE & CR \\
\hline & & & & OCI_8 & 0.819 & & \\
\hline & & & & OCI_9 & 0.777 & & \\
\hline & & & Intensity & IWO_2 & 0.652 & 0.605 & 0.884 \\
\hline & & & & IWO_5 & 0.815 & & \\
\hline & & & & IWO_6 & 0.823 & & \\
\hline & & & & IWO_7 & 0.828 & & \\
\hline
\end{tabular}

The measurement model achieved convergent validity with measurement loadings $>0.5$, average variance extracted $>0.5$ and convergent reliability $>0.7$. The discriminant validity of every latent variable was assessed to ensure that each latent variable is subjectively independent of other indicators. Two measures were used: the Fornell and Larcker (1981) criterion and the cross-loading criterion (Chin, 1998a). According to them, a latent variable should explain the variance of its own indicators better than that of other latent variables. This is to ensure that no multi-collinearity exists amongst the latent variables. In this instance, the AVE of a latent variable was higher than the squared correlations between the latent variable and all other variables (Chin, 2010; Chin, 1998b; Fornell \& Larcker, 1981). Table 6 presents the latent variable correlations. 


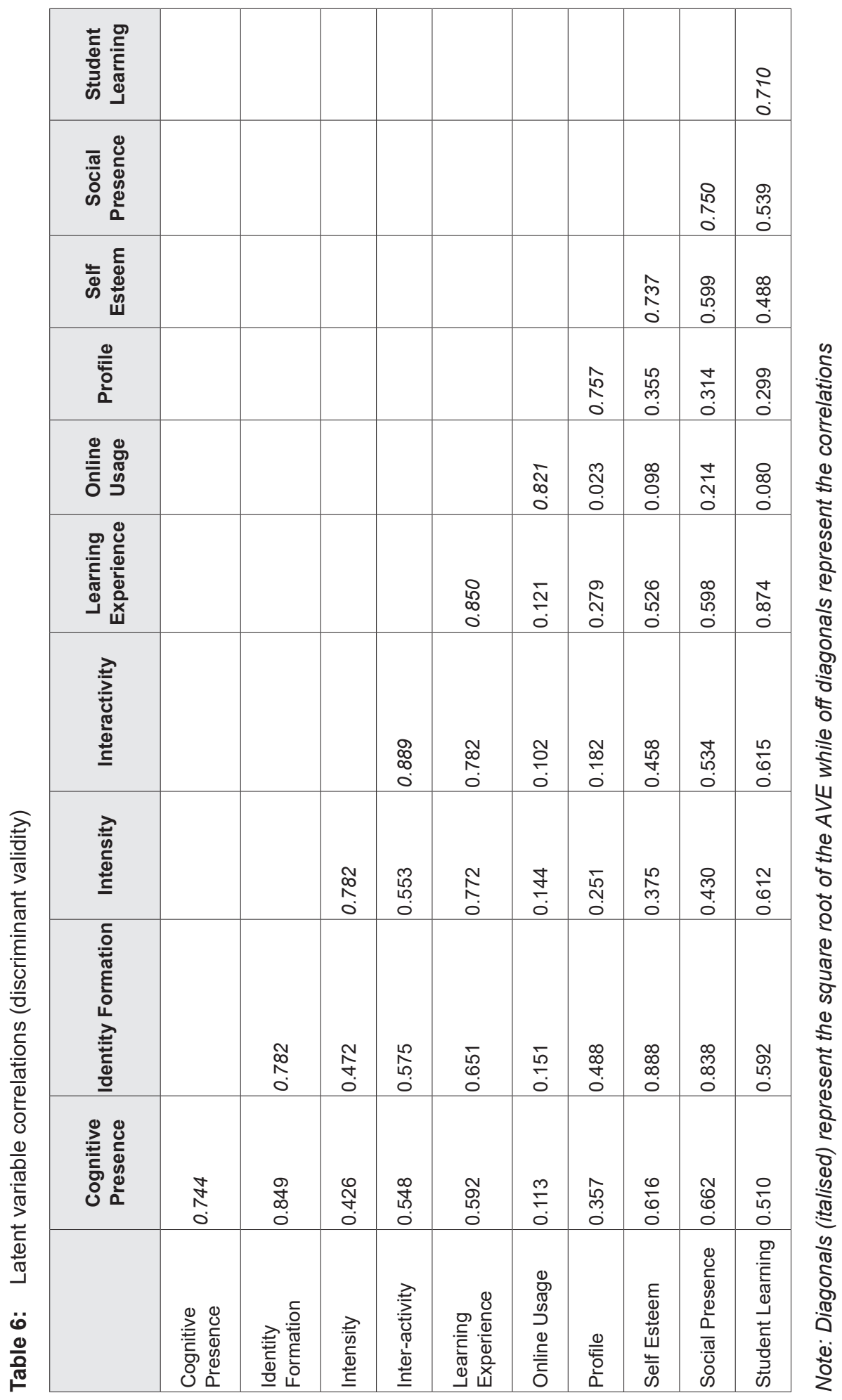


According to the Fornell and Larcker criterion (1981), the values of the diagonals MUST be higher than those of the row and column. From this table it is clear that the respondents were able to understand and discriminate between the different variables, as the diagonal correlations are higher than the off-diagonal correlations.

Table 7 presents the cross loadings of the measurement and latent variables.

Table 7: Cross loadings of measurement and latent variables

\begin{tabular}{|c|c|c|c|c|c|c|c|c|}
\hline & $\begin{array}{l}\text { Online } \\
\text { Usage }\end{array}$ & $\begin{array}{l}\text { Cognitive } \\
\text { Presence }\end{array}$ & $\begin{array}{c}\text { Self } \\
\text { Esteem }\end{array}$ & $\begin{array}{c}\text { Social } \\
\text { Presence }\end{array}$ & Profile & $\begin{array}{c}\text { Student } \\
\text { Learning }\end{array}$ & Interactivity & Intensity \\
\hline AULP & 0.692 & 0.011 & 0.059 & 0.118 & -0.017 & 0.021 & 0.026 & 0.003 \\
\hline NOC & 0.936 & 0.135 & 0.109 & 0.228 & 0.054 & 0.086 & 0.132 & 0.169 \\
\hline SNU & 0.817 & 0.072 & 0.052 & 0.137 & -0.025 & 0.063 & 0.037 & 0.108 \\
\hline YP_1 & 0.064 & 0.690 & 0.409 & 0.364 & 0.279 & 0.312 & 0.327 & 0.254 \\
\hline YP_2 & 0.113 & 0.752 & 0.465 & 0.519 & 0.241 & 0.398 & 0.451 & 0.257 \\
\hline YP_3 & 0.121 & 0.775 & 0.500 & 0.570 & 0.221 & 0.378 & 0.451 & 0.298 \\
\hline YP_4 & 0.058 & 0.693 & 0.341 & 0.450 & 0.201 & 0.325 & 0.329 & 0.292 \\
\hline YP_5 & 0.044 & 0.786 & 0.449 & 0.544 & 0.309 & 0.476 & 0.463 & 0.426 \\
\hline YP_6 & 0.063 & 0.764 & 0.463 & 0.434 & 0.274 & 0.328 & 0.370 & 0.314 \\
\hline YP_7 & 0.114 & 0.739 & 0.550 & 0.538 & 0.325 & 0.418 & 0.436 & 0.364 \\
\hline SYS_1 & 0.001 & 0.386 & 0.707 & 0.380 & 0.308 & 0.359 & 0.282 & 0.264 \\
\hline SYS_10 & 0.092 & 0.474 & 0.709 & 0.497 & 0.238 & 0.398 & 0.341 & 0.251 \\
\hline SYS_11 & 0.175 & 0.383 & 0.676 & 0.445 & 0.268 & 0.353 & 0.336 & 0.210 \\
\hline SYS_2 & 0.058 & 0.514 & 0.830 & 0.515 & 0.312 & 0.477 & 0.398 & 0.345 \\
\hline SYS_3 & 0.046 & 0.426 & 0.707 & 0.378 & 0.261 & 0.348 & 0.335 & 0.229 \\
\hline SYS_4 & 0.068 & 0.529 & 0.810 & 0.451 & 0.306 & 0.383 & 0.363 & 0.329 \\
\hline SYS_5 & 0.088 & 0.426 & 0.747 & 0.423 & 0.270 & 0.276 & 0.264 & 0.288 \\
\hline SYS_6 & 0.042 & 0.471 & 0.806 & 0.453 & 0.274 & 0.420 & 0.367 & 0.297 \\
\hline SYS_7 & 0.114 & 0.396 & 0.661 & 0.406 & 0.146 & 0.249 & 0.307 & 0.183 \\
\hline SYS_8 & 0.079 & 0.545 & 0.777 & 0.527 & 0.246 & 0.414 & 0.433 & 0.326 \\
\hline SYS_9 & 0.040 & 0.403 & 0.645 & 0.354 & 0.232 & 0.226 & 0.252 & 0.288 \\
\hline PYA_3 & 0.173 & 0.323 & 0.312 & 0.623 & 0.248 & 0.327 & 0.236 & 0.256 \\
\hline PYA_4 & 0.155 & 0.376 & 0.373 & 0.737 & 0.219 & 0.380 & 0.343 & 0.324 \\
\hline PYA_5 & 0.205 & 0.520 & 0.528 & 0.774 & 0.228 & 0.460 & 0.400 & 0.408 \\
\hline PYA_6 & 0.181 & 0.533 & 0.522 & 0.806 & 0.220 & 0.450 & 0.442 & 0.381 \\
\hline PYA_7 & 0.179 & 0.571 & 0.518 & 0.802 & 0.252 & 0.396 & 0.437 & 0.262 \\
\hline PYA_8 & 0.118 & 0.541 & 0.404 & 0.771 & 0.259 & 0.394 & 0.474 & 0.340 \\
\hline PYA_9 & 0.114 & 0.558 & 0.442 & 0.717 & 0.231 & 0.408 & 0.429 & 0.276 \\
\hline
\end{tabular}




\begin{tabular}{|c|c|c|c|c|c|c|c|c|}
\hline & $\begin{array}{l}\text { Online } \\
\text { Usage }\end{array}$ & $\begin{array}{l}\text { Cognitive } \\
\text { Presence }\end{array}$ & $\begin{array}{c}\text { Self } \\
\text { Esteem }\end{array}$ & $\begin{array}{c}\text { Social } \\
\text { Presence }\end{array}$ & Profile & $\begin{array}{l}\text { Student } \\
\text { Learning }\end{array}$ & Interactivity & Intensity \\
\hline IYS_1 & 0.057 & 0.344 & 0.326 & 0.336 & 0.734 & 0.270 & 0.171 & 0.248 \\
\hline IYS_2 & -0.051 & 0.234 & 0.203 & 0.140 & 0.796 & 0.148 & 0.081 & 0.168 \\
\hline IYS_3 & -0.013 & 0.209 & 0.218 & 0.226 & 0.740 & 0.214 & 0.140 & 0.178 \\
\hline IYS_5 & 0.053 & 0.260 & 0.294 & 0.205 & 0.758 & 0.246 & 0.139 & 0.144 \\
\hline OLE_1 & 0.012 & 0.481 & 0.426 & 0.442 & 0.329 & 0.661 & 0.424 & 0.389 \\
\hline OLE_10 & 0.007 & 0.292 & 0.219 & 0.289 & 0.155 & 0.710 & 0.440 & 0.422 \\
\hline OLE_2 & 0.086 & 0.409 & 0.456 & 0.399 & 0.292 & 0.725 & 0.429 & 0.443 \\
\hline OLE_4 & 0.180 & 0.355 & 0.363 & 0.444 & 0.176 & 0.693 & 0.420 & 0.472 \\
\hline OLE_5 & 0.120 & 0.331 & 0.366 & 0.353 & 0.182 & 0.754 & 0.436 & 0.455 \\
\hline OLE_6 & -0.048 & 0.295 & 0.280 & 0.297 & 0.157 & 0.740 & 0.472 & 0.417 \\
\hline OLE_7 & -0.020 & 0.337 & 0.243 & 0.393 & 0.214 & 0.752 & 0.481 & 0.514 \\
\hline OLE_8 & 0.085 & 0.383 & 0.426 & 0.382 & 0.218 & 0.669 & 0.387 & 0.371 \\
\hline OLE_9 & 0.099 & 0.390 & 0.363 & 0.458 & 0.197 & 0.675 & 0.433 & 0.414 \\
\hline OCl_1 & 0.081 & 0.474 & 0.377 & 0.450 & 0.191 & 0.534 & 0.750 & 0.432 \\
\hline OCl_2 & -0.004 & 0.349 & 0.299 & 0.323 & 0.108 & 0.429 & 0.687 & 0.294 \\
\hline OCl_3 & 0.141 & 0.500 & 0.402 & 0.472 & 0.171 & 0.479 & 0.823 & 0.456 \\
\hline OCl_4 & 0.141 & 0.452 & 0.409 & 0.420 & 0.096 & 0.439 & 0.760 & 0.414 \\
\hline OCl_5 & 0.087 & 0.458 & 0.424 & 0.473 & 0.183 & 0.459 & 0.809 & 0.400 \\
\hline OCl_6 & 0.069 & 0.425 & 0.393 & 0.392 & 0.164 & 0.474 & 0.804 & 0.494 \\
\hline OCl_7 & 0.074 & 0.386 & 0.270 & 0.398 & 0.060 & 0.451 & 0.799 & 0.403 \\
\hline OCl_8 & 0.063 & 0.405 & 0.332 & 0.374 & 0.096 & 0.535 & 0.819 & 0.489 \\
\hline OCl_9 & 0.053 & 0.401 & 0.315 & 0.451 & 0.203 & 0.520 & 0.777 & 0.483 \\
\hline IWO_2 & 0.189 & 0.311 & 0.270 & 0.310 & 0.149 & 0.365 & 0.396 & 0.652 \\
\hline IWO_5 & 0.143 & 0.368 & 0.317 & 0.392 & 0.195 & 0.495 & 0.461 & 0.815 \\
\hline IWO_6 & 0.012 & 0.356 & 0.344 & 0.329 & 0.208 & 0.558 & 0.462 & 0.823 \\
\hline IWO_7 & 0.096 & 0.331 & 0.254 & 0.322 & 0.190 & 0.467 & 0.450 & 0.828 \\
\hline IWO_8 & 0.147 & 0.286 & 0.267 & 0.317 & 0.230 & 0.477 & 0.373 & 0.756 \\
\hline
\end{tabular}

According to Chin (2010), the loadings of an indicator on its assigned latent variable should be higher than its loadings on all other latent variables. Table 7 shows the discriminant validity and convergent validity of latent variables used in this study. To ensure discriminant validity, bold loadings should be higher than all other loadings within the same row, whereas convergent validity is achieved when bold loadings are higher than all other loadings within the same column. Convergent reliability is also achieved when AVE exceeds 0.5 (Bagozzi \& Yi, 1988; Fornell \& Larcker, 1981). From table 7 it is clear that the cross loadings of the measurement indicators are the highest on the prescribed latent variables and therefore validity and reliability have been achieved. 


\subsubsection{Results of open-ended questions}

From the five open-ended questions, interesting results were obtained which not only supported existing results in the literature but also confirmed new facts. Firstly, "what students like about the usage of online networks for learning purpose" included aspects like easy, fast and convenient; you can create and share information; you can obtain new information; expands thinking abilities/creative ideas; allows for instant replies/immediacy/instantaneous; encourages interactions; accessible; visual; can ask questions socially; obtain knowledge and flexibility. For example, a number of students said, "it is easier to upload and share information and it is efficient and convenient". Secondly, "what students dislike about the usage of online networks for learning purposes" included reasons such as delayed feedback; unreliable/ false information; lack of privacy; emotionless; fear of spam/strangers/stalkers; spreading of rumours; backstabbing; not conclusive; annoying information; distractions (videos, games, YouTube); and information overload. One example is a student saying, "people tend to rely on one person to find and share information".

Thirdly, the advantages of using online networks were pointed out to be up-to-date information; improved socialisation skills; choose and make friends; convenience; don't feel lonely and bored; great for introverts; relationship building; bonding; anonymity; networking; expand knowledge and the reach and richness of the online networks. One example is a student saying, "you don't have to meet in person, so it is great for introverts who can meet new people from around the world", which is interestingly contradictory to the results of Chou and Liu (2005), which indicate that extroverts are more likely to experience benefits from their Internet use than introverts.

Fourthly, the disadvantages mentioned were that it is time consuming; less privacy; disconnection between members; no trust in people because of miscommunication/fake news; bad comments about others/gossip; identity theft/crime/fraud; sometimes friends don't show their true identity/have false identities; misuse of freedom of speech; deception through online information; addictiveness; people become anti-social and cyber bullying. For example, one student said, "you may not know the people you speak to and they may not be what they appear online because they don't always show their true identity". When asked whether they had any other comments, students in general responded that online networks are useful in promoting education to the masses; they help them tremendously in learning. One student said, "overall I love to use online networks for learning purposes", while another stated, "I am going online for learning purposes because it is really informative and people have loads of ideas". Everyone should use online networks more; and it is a good thing. For example, one student said, "online networks encourage learning and increase the opportunity to enhance the learning experience".

\section{Discussion}

Based on the results of the measurement model, it can be deduced that that students and educators should pay attention to three main aspects when using online networks for learning purposes. Firstly, take cognisance of students' identity formation, including their profiles and usage patterns. Do this to ensure that effective communication takes place between the student and lecturer in order to enhance the knowledge creation and the sharing process that takes place through the teaching or training of students, with the ultimate aim of ensuring that a comprehensive knowledge system of a specific domain or subject is established. Secondly, students should pay attention to their online identity formation and usage patterns to ensure 
that they behave ethically and in line with the required values of the institution. Thirdly, although interactivity and intensity of usage might benefit students' learning experience, the results of this study suggest that 'being active online' should not simply be measured by the number of messages posted on online networks or the frequency of online responses or feedback. Rather, it should be measured by the learning experience that takes place through that interactivity and intensity of usage.

\section{Limitations and future research}

The main limitation of this study is that the sample population consisted of randomly selected graduate students from different domains at one university only; hence, the results cannot be generalised. Access to the Internet, the culture of the university and students' creativity requirements might also differ at other universities. Despite these limitations, it is argued that this paper does contribute at an academic level through the exploration of the key constructs and sub-constructs to present a theoretical conceptual framework and to propose a measurement and structural model, which proved to be reliable and valid. The next step is to refine the measurement instrument to focus more on concepts with strong correlations. Future research will then be conducted at other universities. This research is seen as a good starting point for further research because it is posited that the findings of this study made an important contribution in that theoretical clarification is offered of the key constructs.

\section{Conclusions}

In an effort to expand on the knowledge of students' usage of online networks for identity formation and the learning experience, this study investigated the triadic relationship among these constructs. The study revealed the critical role that online networks can play in shaping the identity formation and learning experience of students. In particular, students can benefit from online networks and students are more likely to use online networks if the online networks will enhance the students' identity formation and learning experience. A review of existing literature on online networks, which became a new phenomenon in human communication, interaction and the learning experience, illustrated the need for a new and/or improved measuring scale. The results of the new measurement model confirmed a link between the usage of the Internet for learning purposes (students were more open for information sharing in order to build a sense of belonging, gain group cohesion, encourage participation, obtain feedback, etc.) and identity formation (they tried to increase their self-confidence and selfesteem by establishing a social and cognitive presence through their online profiles and develop positive attitudes, etc.). The students realise the importance of interactivity and intensity in online networks, especially for learning purposes (many adapted their identity to be accepted by the in-groups, managed information to enhance student learning, took responsibility, networked, collaborated, etc.).

To conclude, given the scarcity of research on this new and relatively under-explored area, this study can be seen as an important starting point for future research to clarify and consider the wider implications of identity formation and the learning experience in online networks in theory and in practice. The former may evoke enhancements of research in general and the latter may take place across different areas and sectors. While this article outlined some of the basic concepts and approaches, much remains to be done and several options exist to further extend this initial study. The importance of this is borne out by the following quote from Tang and Ding (2014: 464): 
The Internet is becoming an important information or knowledge source and a widely used communication platform for college students. With the development of Internet technology, virtual interactions among professional persons are being increased quickly, [...] [leading] to the emergence of a virtual networked knowledge society.

\section{Acknowledgement}

This work was partially supported by the National Research Foundation of South Africa.

\section{Bibliography}

Attrill, A. \& Jalil, R. 2011. Revealing only the superficial me: Exploring categorical selfdisclosure online. Computers in Human Behavior, 27, 1634-42. http://dx.doi.org/10.1016/j. chb.2011.02.001

Bagozzi, R.P. \& Yi, Y. 1988. On the evaluation of structural equation models. Journal of the Academy of Marketing Science, 16(1), 74-94. http://dx.doi.org/10.1007/BF02723327

Bargh, J.A. \& McKenna, K.Y. 2004. The internet and social life. Annu. Rev. Psychol., 55, 573-90. http://dx.doi.org/10.1146/annurev.psych.55.090902.141922

Barker, R. 2011. Managing online crisis communication response in a South African bank: A comparative analysis. Communicare, 30(2), 27-50.

Boyd, D.M. \& Ellison, N.B. 2008. Social network sites: Definitions, history and scholarship. Journal of Computer-mediated communication, 13, 210-30. http://dx.doi. org/10.1111/j.1083-6101.2007.00393.x

Brown, A. 2011. Relationships, community and identity in the new virtual society. The Futurist, 29-34.

Cheung, C.M.K., Chiu, P. \& Lee, M.K.O. 2011. Online social networks: Why do students use Facebook?. Computers in Human Behaviour, 27, 1337-1343. http://dx.doi.org/10.1016/j. chb.2010.07.028

Chin, W.W. 1998a. The partial least squares approach to structural equation modeling. In G.A. Marcoulides (Ed.), Modern business research methods. Mahwah, NJ: Lawrence Erlbaum Associates.

Chin, W.W. 1998b. Issues and opinions on structural equation modeling. MIS Quarterly, 22(1), 7-16.

Chin, W.W. 2010. How to write up and report PLS analyses. In V.E. Vinze, W.W. Chin, J. Chou, \& C. Liu. Learning effectiveness in a web-based virtual learning environment: A learner control perspective. Journal of Computer Assisted Learning, 21: 65-76.

Conway, J.M. \& Lance, C.E. 2010. What reviewers should expect from authors regarding common method bias in organisational research. Journal of Business Psychology, 25, 325-34. http://dx.doi.org/10.1007/s10869-010-9181-6

Ellison, N.B., Steinfield, C. \& Lampe, C. 2007. The benefits of Facebook 'friends': Social capital and college students' use of online social network sites. Journal of Computer-Mediated Communication, 12(4), 1143-68. http://dx.doi.org/10.1111/j.1083-6101.2007.00367.x

Fornell, C. \& Larcker, D.F. 1981. Evaluating structural equation models with unobservable variables and measurement error. Journal of Marketing Research, 18(1), 39-50. http://dx.doi. org/10.2307/3151312 
Garrison, D.R., Cleveland-Innes, M. \& Fung, T. 2004. Student role adjustment in online communities of inquiry: Model and instrument validation. Journal of Asynchronous Learning Networks, 8(2), 61-74.

Greenhow, C. \& Robelia, B. 2009. Informal learning and identity formation in online social networks. Learning, Media and Technology, 34(2), 119-40. http://dx.doi. org/10.1080/17439880902923580

Hair, J.F., Black, W.C., Babin, B.J. \& Anderson, R.E. 2010. Multivatirate data analysis: A global perspective, 7th ed.. New Jersey: Prentice Hall.

Hara, N. \& Kling, R. 2000. Student's distress with web-based distance education course: An ethnographic study of participant's experiences. Information, Communication, and Society, 3, 557-579. http://dx.doi.org/10.1080/13691180010002297

Hulland, J. 1999. Use of partial least squares (PLS) in strategic management research: A review of four recent studies. Strategic Management Journal, 20, 195-204. http://dx.doi. org/10.1002/(SICI)1097-0266(199902)20:2<195::AID-SMJ13>3.0.CO;2-7

Hung, S.W. \& Cheng, J.M. 2013. Are you ready for knowledge sharing? An empirical study of virtual communities. Computers and Education, 62, 8-17. http://dx.doi.org/10.1016/j. compedu.2012.09.017

Kirkwood, A. 2008. Getting it from the web: Why and how online resources are used by independent undergraduate learners. Journal of Computer Assisted Learning, 24(5), 372-82. http://dx.doi.org/10.1111/j.1365-2729.2007.00265.x

LaRose, R., Lai, Y.J. Lange, R., Love, B. \& Wu, Y. 2005. Sharing or piracy? An exploration of downloading behaviour. Journal of Computer-Mediated Communication, 11(1): 1-21. http:// dx.doi.org/10.1111/j.1083-6101.2006.tb00301.x

Pempek, T.A., Yermolayeva, Y.A. \& Calvert, S.L. 2008. College students' social networking experiences on Facebook. Journal of Applied Developmental Psychology, 30(3), 27-38.

Podsakoff, P.M. \& Organ, D.W. 1986. Self-reports in organisational research: Problems and prospects 1. Journal of Management, 2(4), 531-44. http://dx.doi. org/10.1177/014920638601200408

Ramayah, T., Lee, J.W.C. \& In, J.B.C. 2011. Network collaboration and performance in the tourism sector. Service Business, 5(4), 411-28. http://dx.doi.org/10.1007/s11628-011-0120-z

Sancho, T. \& De Vries, F. 2014. Virtual learning environments, social media and MOOCs: key elements in the conceptualization of new scenarios in higher education. EADTU Conference 2013. Open Learning, 28(3), 166-70. http://dx.doi.org/10.1080/02680513.2014.888000

Tang, C. \& Ding, X. 2014. Graduate students' creative professional virtual community behaviors and their creativity. Computers in Human Behaviour, 41, 464-470. http://dx.doi. org/10.1016/j.chb.2014.09.055

Taylor, L., Trenkel, V.M., Kupca, V. \& Stefansson, G. 2011. A bootstrap method for estimating bias and variance in statistical multispecies modelling frameworks using highly disparate data sets. Reykjavik: Science Institute, University of Iceland.

Walker, C., Gleaves, A. \& Grey, J. 2006. A study of the difficulties of care and support in new university teachers' work. Teachers and Teaching: Theory and Practice, 12(3), 347-363.

Young, C. \& Strelitz, L. 2014. Exploring patterns of Facebook usage, social capital, loneliness and well-being among a diverse South African student sample. Communicare, 33(1), 57-72. 